\title{
Endometrial hyperplasia as a risk factor of endometrial cancer
}

\author{
Lisa K. Nees ${ }^{1}\left(\right.$ D . Sabine Heublein ${ }^{1} \cdot$ Sahra Steinmacher ${ }^{2}$. Ingolf Juhasz-Böss ${ }^{3} \cdot$ Sara Brucker $^{2} \cdot$ Clemens B. Tempfer $^{4}$. \\ Markus Wallwiener ${ }^{1}$
}

Received: 28 November 2020 / Accepted: 23 December 2021 / Published online: 10 January 2022

(c) The Author(s) 2022

\begin{abstract}
Endometrial hyperplasia (EH) is the precursor lesion for endometrioid adenocarcinoma of the endometrium (EC), which represents the most common malignancy of the female reproductive tract in industrialized countries. The most important risk factor for the development of EH is chronic exposure to unopposed estrogen. Histopathologically, EH can be classified into $\mathrm{EH}$ without atypia (benign $\mathrm{EH}$ ) and atypical EH/endometrial intraepithelial neoplasia (EIN). Clinical management ranges from surveillance or progestin therapy through to hysterectomy, depending on the risk of progression to or concomitant EC and the patient's desire to preserve fertility. Multiple studies support the efficacy of progestins in treating both benign and atypical EH. This review summarizes the evidence base regarding risk factors and management of EH. Additionally, we performed a systematic literature search of the databases PubMed and Cochrane Controlled Trials register for studies analyzing the efficacy of progestin treatment in women with EH.
\end{abstract}

Keywords Endometrial hyperplasia $\cdot$ Endometrial cancer $\cdot$ Benign endometrial hyperplasia $\cdot$ Atypical endometrial hyperplasia $\cdot$ Endometrial intraepithelial neoplasia $\cdot$ Progestin therapy

\section{Introduction}

In industrialized countries, endometrial cancer (EC) represents the most common malignancy of the female reproductive tract. The precursor lesion for endometrioid adenocarcinoma of the endometrium, which comprises the majority of ECs, is endometrial hyperplasia (EH). EH is a noninvasive, abnormal proliferation of the endometrial lining of the uterus and associated with a significant risk of concurrent $\mathrm{EC}$ or progression to EC. The leading symptoms of EH are bleeding disorders in premenopausal women and vaginal bleeding in postmenopausal women. The most important

Markus Wallwiener

markus.wallwiener@med.uni-heidelberg.de

1 Department of Obstetrics and Gynecology, University of Heidelberg, Im Neuenheimer Feld 440, 69120 Heidelberg, Germany

2 Department of Obstetrics and Gynecology, Universität Tübingen, Tübingen, Germany

3 Department of Obstetrics and Gynecology, Universität Freiburg, Freiburg, Germany

4 Comprehensive Cancer Center, Ruhr University Bochum (RUCCC), Bochum, Germany risk factor is chronic exposure to unopposed estrogen. This narrative review aims to give an overview of the classification, risk factors, and management of EH. We searched the following databases: PubMed and Cochrane Controlled Trials register. We performed the final search in March 2021. Additionally, we performed a systematic literature search of the databases PubMed and Cochrane Controlled Trials register for studies analyzing the efficacy of progestin treatment in women with EH.

\section{Classification of EH and risk of progression to EC}

Histologically, EH describes the abnormal proliferation of endometrial glands with a greater gland-to-stroma-ratio than healthy proliferative endometrium but without endometrial stromal invasion. Diagnosis should be based upon histological assessment of a tissue sample obtained by endometrial biopsy, curettage, or hysterectomy. The most widely used classification system for EH is the 2014 World Health Organization (WHO) Classification System which differentiates between: 
- EH without atypia (benign EH) and

- atypical EH/endometrial intraepithelial neoplasia (EIN).

This distinction is particularly important because clinical management of the two conditions is different, depending on the presence or absence of nuclear atypia. Nuclear atypia is defined as nuclear enlargement with or without prominent nucleoli [1]. EH without atypia constitutes a benign lesion without significant somatic genetic changes caused by extensive exposure to estrogen that is not counterbalanced by the protective effects of progestins. If physiological progesterone levels are resumed or if therapeutic progestins are used, the hyperplastic changes regress and the endometrium becomes healthy again in the majority of cases [2]. EH without atypia seems to rarely progress to EC although evidence supporting this statement is poor. For example, in a case series published in 1985, benign EH only progressed to EC in two (1.6\%) out of 122 patients. The first patient with simple hyperplasia developed atypical EH and subsequently EC 11 years after the first diagnosis of EH. The second patient had complex EH which progressed to EC 8.3 years after the initial diagnosis. Neither patient had received progestin treatment or died of their disease [3].

In a case-control study nested in a cohort of 7,947 women diagnosed with EH from 1970 to 2002, 138 women were diagnosed with EC, on average 6 years after the initial diagnosis of $\mathrm{EH}[4,13]$. The cumulative 20-year progression risk was less than 5\% for EH without atypia but $28 \%$ for atypical EH. Specifically, for EH without atypia, the cumulative progression risk increased from $1.2 \%$ (95\% CI, $0.6 \%$ to $1.9 \%)$ to $1.9 \%$ within 4 years (95\% CI, $1.2 \%$ to $2.6 \%$ ), to $4.6 \%$ within 9 years (95\% CI, 3.3\% to 5.8\%) and up to 19 years after $\mathrm{EH}$ diagnosis. For women with atypical $\mathrm{EH}$, the cumulative risk increased from $8.2 \%$ (95\% CI, $1.3 \%$ to $14.6 \%$ ) to $12.4 \%$ within 4 years ( $95 \% \mathrm{CI}, 3.0 \%$ to $20.8 \%$ ), to $27.5 \%$ within 9 years $(95 \% \mathrm{CI}, 8.6 \%$ to $42.5 \%)$ and up to 19 years after the diagnosis of EIN.

Atypical EH has many similarities with endometrioid EC at the molecular level [4]. Concurrent EC was found in 37\% of women with atypical $\mathrm{EH}$ in a retrospective case series including 219 patients with EIN combined with a review of 31 published studies including a total of 2571 patients [5]. Other studies have documented a risk of concomitant EC in up to $50 \%$ of patients with atypical EH [6-9]. A high risk of concomitant EC among women with atypical EH is also consistent with the high risk of progression to EC observed among women with EH undergoing progestin treatment. This risk of progression to EC has been described to be between 15 and $28 \%$ [10-12]. For example, a retrospective cohort study investigated 242 women with atypical EH, of whom $74 \%$ received progestin therapy [12]. The rate of progression to EC was significantly higher without progestin treatment (101.4 versus 20.5 per 1000 woman-years).
During a median follow-up of five years, $15 \%$ of all women with atypical EH developed EC. The risk for development of EC in women with atypical EH has been shown to be diminished approximately threefold to fivefold when treated with progestin [12]. Another important issue to be considered when assessing the concurrent or future risk of EC among women with atypical EH is the fact that it may be difficult to histopathologically distinguish EIN from EC. Illustrating these diagnostic difficulties, Trimble et al. found over- or underdiagnosis in almost every third specimen [13]. Specifically, independent gynecologic pathologists reviewed 289 endometrial biopsy specimens from women with a community diagnosis of atypical $\mathrm{EH}$ and found that in $25 \%$ the diagnosis was less severe than atypical EH, whereas in $29.1 \%$ EC was already present. This suggests a significant overlap between the different diagnoses of EH without atypia, atypical EH, and EC both in clinical practice as well as in the literature. Therefore, it is reasonable to treat atypical $\mathrm{EH}$ as the equivalent of early EC when counseling affected patients.

\section{Risk factors of EH}

As its precursor lesion, the risk factors for developing EH are closely related to the well-known risk factors for endometrioid adenocarcinoma of the endometrium. The most important risk factor for both $\mathrm{EH}$ and $\mathrm{EC}$ is a chronic imbalance of estrogen and progestin in favor of estrogen [14-18]. Exposure to excessive estrogen without the protective effect of progestin can be endogenous or exogenous in nature. Other risk factors include genetic factors such as hereditary nonpolyposis colorectal cancer (HNPCC, or Lynch syndrome) and Cowden syndrome, which is rare and in most cases related to a mutation in the phosphatase and tensin homologue deleted on chromosome 10 (PTEN) gene, located on chromosome 10q23.31 [19-22].

\section{Endogenous estrogen exposure}

Examples of excessive endogenous exposure to estrogen include obesity, chronic anovulation, early menarche, and late menopause as well as the presence of estrogen-secreting tumors. In obese women, a high amount of adipose tissue is closely associated with higher local and circulating levels of estradiol. This can be explained through various mechanisms. Firstly, an increase in adrenal secretory activity is often observed, which leads to an increase in androgen precursors. These precursors may then be converted to estradiol in peripheral tissues. Secondly, the conversion rate of androstenedione to estrone by the enzyme aromatase rises as this conversion primarily takes place in adipose tissue. Lastly, higher concentrations of estradiol can be found in 
obese patients as plasma levels of estradiol-binding sex hormone-binding globulin (SHBG) are typically depressed in this patient population [23]. These pathophysiological observations are consistent with clinical findings. For example, in a retrospective cohort study including 916 premenopausal women with abnormal uterine bleeding, patients with a body mass index of over $30 \mathrm{~kg} / \mathrm{m}^{2}$ developed complex hyperplasia or EC 4 times more often than lean women $(95 \%$ CI, 1.36-11.74) [24].

Chronic anovulation is another important risk factor for EH. When anovulation occurs, sex hormone production is not cyclical as in regularly ovulating premenopausal women. Without ovulation, estrogen levels still dominate without the opposing effect of progesterone produced by the corpus luteum after ovulation. This imbalance leads to a continued proliferation of the endometrium resulting in a higher risk of developing EH and eventually endometrioid EC. Common settings associated with anovulation include polycystic ovary syndrome (PCOS), hyperprolactinemia, and perimenopausal hormonal status. In 2009, a meta-analysis of four case-control studies including a total of 4056 women showed an almost threefold risk of developing EC for women with PCOS compared to the general population (OR 2.70, 95\% CI, 1.00-7.29) [25]. In 2012, a subsequent meta-analysis of the same studies including another cross-sectional study, confirmed this risk elevation in PCOS patients (OR 2.89, 95\% CI, 1.52-5.48) [26]. However, these results need to be interpreted with caution since other authors suspected that the risk increase was exaggerated due to risk factors commonly associated with PCOS such as obesity and diabetes and skewing of the risk estimates due to a potential selection bias in some of the studies [27, 28].

Hormone-secreting tumors can cause an endogenous sex hormone imbalance. For example, granulosa cell tumors represent potentially estrogen-secreting tumors of the ovary. Consequently, $\mathrm{EH}$ is diagnosed in $25 \%$ to $50 \%$ of women with granulosa cell tumors of the ovary [29, 30]. If EH is diagnosed in a patient without other known risk factors, estrogen-secreting tumors should therefore be excluded.

\section{Exogenous estrogen exposure}

Estrogen therapy should always be supplemented with a progestin in women with an intact uterus. Unopposed estrogen therapy in women with an intact uterus increases the risk of developing EH and then EC in both premenopausal and in postmenopausal women. This is well illustrated in a meta-analysis including 45 randomized studies of hormone replacement therapy over a minimum period of 12 months in postmenopausal patients [31]. The authors documented a significantly increased risk of EH when women were treated with estrogen alone. The risk increased after 12 months of unopposed treatment with moderate or high-dose estrogen therapy (OR 8.4 and 10.7, respectively) and after 18 to 24 months of treatment with low-dose estrogen therapy (OR 2.4). Other studies have assessed the risk of developing EC in women treated with unopposed estrogens and found a 1.5- to tenfold relative risk increase [32-36].

Tamoxifen, which is one of the most important agents for endocrine treatment of hormone receptor-positive breast cancer, has been associated with an increased risk for developing EH and EC [37]. Several small studies concluded that tamoxifen-related ECs are mostly diagnosed at an early stage with an overall good prognosis [38-40]. In contrast, a nationwide case-control study conducted in the Netherlands including 309 patients with a diagnosis of EC after a history of breast cancer and 860 patients with a history of breast cancer but without EC reported a worse prognosis in long-term tamoxifen users due to a higher risk of EC with a higher tumor stage and a less favorable histology [41]. In this study, a longer duration of tamoxifen treatment was associated with a significantly increased risk of EC. The relative risks were $2.0(1.2-3.2)$ for 2 to 5 years of tamoxifen and $6.9(2.4-19.4)$ for at least 5 years of tamoxifen compared to no tamoxifen therapy. In addition, long-term use of tamoxifen ( $\geq 2$ years) was associated with more stage III and IV ECs compared with non-users (17.4\% and 5.4\%, respectively, $\mathrm{p}<0.01)$. However, in patients with hormone receptor positive breast cancer the benefits of endocrine therapy with tamoxifen clearly predominate in comparison with the increased risk of EC [41, 42]. A prophylactic use of tamoxifen in healthy patients, on the other hand, should be discussed critically in view of the available data. Two studies suggest that the elevated risk of EH and EC in tamoxifen users might be limited to postmenopausal women. In one of these studies, no significant difference in the development of endometrial abnormalities was observed in premenopausal patients treated with tamoxifen compared to women who received placebo. In contrast, the risk ratio among postmenopausal women was 4.01 (95\% CI, 1.70 - 10.90) [43]. Another study found significantly more endometrial abnormalities in postmenopausal women treated with tamoxifen, while no differences in endometrial thickness, uterine volume, or histopathological results were reported in premenopausal patients treated with tamoxifen compared with controls [44]. This clinical aspect is important since tamoxifen can be replaced by aromatase inhibitors in postmenopausal breast cancer patients but still represents the standard of care for premenopausal breast cancer patients.

\section{Lynch syndrome}

HNPCC or Lynch syndrome is a genetic disorder inherited in an autosomal dominant fashion. Due to mutations in DNA mismatch-repair (MMR) genes like MSH2, MLH1, MSH6 and PMS2 leading to microsatellite instability (MSI) patients 
with HNPCC have a lifetime risk of $40-60 \%$ for development of EC [45]. In a recent prospective cross-sectional study conducted in the United Kingdom 500 women with atypical $\mathrm{EH}$ or EC were tested for Lynch-Syndrome. In total, 16/500 participants had Lynch-Syndrome (3.2\%, 95\% CI $1.8 \%$ to $5.1 \%)$ and 11 more $(2.5 \%)$ were tested positive for MMR variants of uncertain significance. The proportion of affected patients with Lynch-Syndrome (3.2\%) in this study population was similar to colorectal cancer. Thus, the authors suggest unselected screening of atypical EH and EC for MSI [46]. EC is also diagnosed at a younger age in women with Lynch-Syndrome [47]. In a study including 69 women with Lynch-Syndrome-associated EC, $18 \%$ were diagnosed under 40 years, compared with a mean age of 60 years in women without Lynch-Syndrome [48]. Molecular alterations like MSI seem to take place early in the degenerative process. Studies suggest that determination of molecular changes like MSI in patients with atypical EH could help to identify early carcinogenesis and synchronous endometrial carcinoma [49, 50]. Experts recommend annual hysteroscopy and endometrial sampling in women with Lynch Syndrome beginning at age 35 [51]. This recommendation is supported by data from a prospective observational cohort study including 41 women with HNPCC comparing the accuracy of office hysteroscopy and endometrial sampling with transvaginal ultrasound alone. While both diagnostic methods had a similar specificity, the positive likelihood ratio was higher and the negative likelihood ratio lower in office hysteroscopy and endometrial sampling compared to transvaginal ultrasound [52]. However, larger studies are needed to confirm these findings.

\section{Management of EH}

A number of different aspects should be considered in the treatment of EH. Depending on the histological features and the patient's medical history, all established risk factors for progression to EC or the concurrent presence of the disease should be determined. In addition, a specialized gyneco-pathologist should be consulted given the diagnostic uncertainties of differentiating between $\mathrm{EH}$, atypical $\mathrm{EH}$, and EC. The 2014 WHO classification of EH for the two$\mathrm{EH}$ without atypia (benign $\mathrm{EH}$ ) and atypical EH-should be applied in order to guarantee comparability of histopathological data both in clinical practice and in academic studies. The presence or absence of nuclear atypia is the most important factor for appropriate therapy planning and monitoring. EH is mostly associated with excessive exposure to unopposed estrogen. It is therefore crucial to supplement any form of treatment by removing the source of excessive estrogen, for example, by encouraging obese patients to lose weight, stopping any type of unopposed estrogen therapy, treating anovulation (e.g., in PCOS patients or patients with hyperprolactinemia), or identifying and removing estrogensecreting tumors. Additionally, it is important to consider the necessity of contraception and fertility issues in premenopausal EH patients, depending on their family planning status. The most important treatment options for EH can be divided into three subgroups:

1. Surveillance (watchful waiting)

2. Surgical treatment (hysterectomy \pm bilateral salpingooophorectomy)

3. Progestin therapy

\section{Surveillance}

Surveillance alone might be an option for patients with benign EH (EH without atypia) and desire to preserve fertility when progestin therapy is not an option. In these cases it is especially important to eliminate potential sources of excess estrogen. Follow-up endometrial sampling should be conducted to exclude progression to atypical EH or EC given the $5 \%$ risk of progression over 20 years [4].

\section{Surgical treatment}

The risk of disease progression or simultaneous EC is high for atypical EH. Thus, hysterectomy should be recommended to most patients with atypical EH, especially to all postmenopausal patients and to premenopausal women who have completed their families. If surgery is not an option or if the patient wishes to preserve her fertility, progestin treatment with close follow-up might be considered as an alternative [2]. Total hysterectomy is the curative treatment of choice in patients with atypical EH eligible for surgery [53]. A supracervical approach should not be recommended as the cervix might be affected by precancerous lesions. Intraoperatively, the uterine specimen can be assessed for malignant disease by gross inspection and/or frozen section. However, the sensitivity of frozen section as a method for detecting EC during surgery is low at rates of only $73 \%-88 \%$ [54-56]. Of note, one study even reported a sensitivity of only $27 \%$ [57]. In addition, bilateral salpingo-oophorectomy should be considered in women with early EC given the high prevalence of ovarian cancer among young women with EC. For example, in a systematic literature review, 2904 cases of women with simultaneous EC and ovarian cancer (SEOC) were identified with 1035 (36\%) of them being premenopausal or $<50$ years of age [96]. The proportion of women with SEOC among all reported EC cases was 842/23,498 (3\%). Microsatellite instability with mutations in mismatch repair genes compatible with HNPCC were identified in $40 \%$ of women analyzed. Thus, young women with EC have a high risk of synchronous ovarian cancer. In young women with 
EC, bilateral salpingo-oophorectomy or careful histological assessment of both ovaries is recommended in order to confirm or rule out SEOC [58]. HNPCC testing should be offered to all young women with EC. The option of bilateral salpingo-oophorectomy should be discussed individually with every patient taking into account potential risks of the additional procedure as well as long-term adverse effects and the risk of ovarian cancer.

\section{Progestin therapy}

Multiple studies support the efficacy of progestins in treating both benign and atypical EH [59-64]. Progestin therapy is therefore the most widely used approach for treating women with EH. The progestin supply activates progesterone receptors, which leads to decidualization of the endometrial stroma and subsequently to endometrial thinning [2]. Especially in premenopausal women with benign $\mathrm{EH}$ and a desire to preserve fertility, progestin administration should be the therapy of first choice. When a high risk of concurrent EC is suspected, initial endometrial biopsy should be supplemented with a dilation and curettage procedure to exclude any malignancy. Progestin therapy is contraindicated in patients with thrombophilia, hormone receptor-positive breast cancer, liver failure, known allergy to progestins and during pregnancy.

Different types of progestins and different routes of administration have been proven to be effective in treating EH. While orally administered megestrol acetate and medroxyprogesterone acetate (MPA) were formerly the most widely used therapeutics, the levonorgestrel-releasing intrauterine device (LNG-IUD), which releases $20 \mu \mathrm{g}$ of LNG over $24 \mathrm{~h}$ (LNG 52/5) for a period of 4 to 5 years, has replaced oral progestin therapies as current first-line therapy in many countries. Indeed, in patients with benign $\mathrm{EH}$, regression to healthy endometrium has been reported in up to $90 \%$ upon treatment with the LNG 52/5 IUD [65, 66]. In women with atypical EH and/or early EC, treatment with the LNG 52/5 IUD has been shown to lead to complete regression in approximately $75-85 \%$ of patients [2]. Randomized trials reported that the LNG 52/5 IUD is more effective than orally administered progestins in the treatment of EH, while having fewer systemic side effects and providing effective contraception [67-69]. Through its local effect on the endometrium, the LNG 52/5 IUD evades absorption and metabolism by the intestinal flora and the liver, where progestin is associated with sedative effects $[70,71]$. Other side effects of orally administered progestins include bloating, nausea, headaches, and mood swings or even depression. Irregular vaginal bleeding patterns, including spotting, represent another typical side effect of progestin treatment. This is true for both oral and intrauterine treatments. A meta-analysis of 34 observational studies found no difference in vaginal bleeding irregularities in women treated with oral progestins as compared with women who received the LNG 52/5 IUD [72].

Although potentially more effective, the LNG 52/5 IUD might not constitute an appropriate therapeutic approach for all patients with EH. Oral progestins might be a better option for women who are eager to have children, patients with IUD-related dysmenorrhea, or anatomic factors complicating IUD placement. When treating EH with oral progestins, patients should receive a continuous therapeutic dose over three to six months. Therapeutics include progestin monotherapies and combined estrogen-progestin drugs (oral contraceptives). As previously mentioned, the most common oral progestin monotherapeutics are megestrol acetate and MPA [64, 65]. The doses of MPA used in the literature depend on the type of EH and vary from $10 \mathrm{mg}$ per day for benign $\mathrm{EH}$ to $600 \mathrm{mg}$ per day in EIN [73]. Overall, in order to treat EIN progestin therapy should be administered continuously and in higher doses than for treatment of benign EH [66, 74-76]. Moreover, cyclic progestin therapies are more frequently associated with vaginal bleeding irregularities than continuous dosing.

However, these medications do not provide contraception. As progestin medications are contraindicated during pregnancy, additional birth control should be advised to premenopausal women using these therapies. To date, no high-quality data supporting the use of oral contraceptives in the treatment of EH are available, although the effect of progesterone dominates at the tissue site in combined estrogen-progestin drugs [77].

The therapeutic success of progestin therapy should be monitored by endometrial sampling on a 3-monthly or 6-monthly basis. Especially in women with atypical $\mathrm{EH}$ a thorough follow-up is mandatory. If regression to a healthy endometrium can be demonstrated histologically, premenopausal patients who would like to preserve fertility may end progestin therapy after 3 to 6 months and try to become pregnant. In fact, after successfully completing progestin therapy, some women with $\mathrm{EH}$ are able to conceive. A meta-analysis including 28 studies with a total of 1038 patients with atypical EH or early EC reported that $34 \%$ of patients conceived after progestin treatment $(95 \%$ CI, $30-38 \%$ ) and $20 \%$ of these women actually delivered a baby [73].

In postmenopausal women or premenopausal women without an immediate desire to become pregnant, progestin therapy should be continued as maintenance therapy with further follow-up via endometrial sampling, especially if vaginal bleeding abnormalities recur $[78,79]$. If atypical EH persists or if EC develops despite continued progestin therapy, hysterectomy is recommended. 


\section{Systematic literature search "efficacy of progestin treatment in women with EH"}

We performed a literature search of the databases PubMed and Cochrane Controlled Trials register (search date 30-06-2020) using the search terms: ((()("progestinic"[All Fields] OR "progestinics"[All Fields]) OR "progestins"[Pharmacological Action]) OR "progestins"[MeSH Terms]) OR "progestins"[All Fields]) OR "progestin"[All Fields]) AND (("endometrial hyperplasia"[MeSH Terms] OR ("endometrial"[All Fields] AND "hyperplasia"[All Fields])) OR "endometrial hyperplasia"[All Fields]) AND (((()("therapeutics"[MeSH Terms] OR "therapeutics"[All Fields]) OR "treatments"[All Fields]) OR "therapy"[MeSH Subheading]) OR "therapy"[All Fields]) OR "treatment"[All Fields]) OR "treatment s"[All Fields]). This search yielded 749 citations. We then restricted the search to the last 20 years (January 2000 to June 2020) resulting in 385 citations. The abstracts of these publications were screened and 33 of them were selected that included original data from retrospective or prospective comparisons of endocrine treatment options with progestins compared to placebo or no treatment. These studies were retrieved in full and a reference search was performed, yielding an additional 3 citations. In summary, we identified 7 systematic reviews and/or meta-analyses [65, 66, 72, 73, 80-82], 21 cohort studies [59, 61, 74-76, 78, 79, 83-96], 1 case-control study [60], 6 randomized controlled trials [97-102], and one case report [103]. Table 1 shows the study characteristics and results of the 6 randomized clinical trials with patient-specific data analyzing the efficacy of progestin treatment in women with EH. Table 2 shows the study characteristics and results of the 21 cohort studies with patient-specific data analyzing the efficacy of progestin treatment in women with $\mathrm{EH}$.

$\mathrm{EH}$, endometrial hyperplasia; CS, cohort study; MPA, medroxyprogesterone acetate; MGA, megestrol acetate; NETA, norethisterone acetate; EC, endometrial cancer; G1, grading 1; LNG, levonorgestrel; IUD, intrauterine device; $\mathrm{PR}$, progesterone receptor; RCT, randomized controlled trial; BMI, body mass index; CR, complete response.

$\mathrm{EH}$, endometrial hyperplasia; CS, cohort study; MPA, medroxyprogesterone acetate; MGA, megestrol acetate; NETA, norethisterone acetate; EC, endometrial cancer; G1, grading 1; LNG, levonorgestrel; IUD, intrauterine device; $\mathrm{PR}$, progesterone receptor; RCT, randomized controlled trial; BMI, body mass index; CR, complete response.

In addition to the RCTs and CS listed in Tables 1 and 2, we identified 1 case-control study [60] and 1 case report [103]. In the case-control study, Montz et al. assessed the feasibility of using a. LNG-IUD to treat presumed FIGO stage IA, grade $1 \mathrm{EC}$ in women at high risk for perioperative complications, i.e. American Society of Anesthesiologists class III or IV. Twelve patients have been followed up to 36 months; results of biopsies were negative in 7 of 11 at 6 months and 6 of 8 at 12 months. No IUD-related complications, except for expulsion, occurred. Sixteen complications (one fatal) occurred in 9 of the 15 control patients who underwent surgery. The authors conclude that LNG-IUD is a feasible treatment with special relevance for patients with early EC and a high risk of surgical complications. In the case report, Kresowik et al. report a patient with atypical endometrial hyperplasia who developed an adenocarcinoma of the endometrium after 6 months of treatment with a LNG-IUD. The authors advocate caution when using this therapy and recommend rigorous and in-depth shared decision making.

\section{Systematic reviews of progestin treatment for EH or early EC}

In a systematic review and meta-analysis of 7 randomized trials with 766 patients, Abu Hashim et al. found that the LNG-IUD achieved a higher regression rate than oral progestins after 3, 6, 12, and 24 months (OR, 7.46; 95\% CI, 2.55-21.78). Subgroup analysis showed that the effect of treatment with the LNG-IUD was superior for both simple and complex EH [65]. In another systematic review and meta-analysis including 24 observational studies and 1001 patients, Gallos et al. confirmed the superiority of the LNGIUD to oral progestins both for complex EH (pooled regression rate, $66 \%$ vs $92 \% ; p<0.01$ ) and atypical EH (pooled regression rate, $69 \%$ vs $90 \% ; p=0.03$ ) [66]. In a second meta-analysis of 34 observational studies, Gallos et al. investigated the efficacy of conservative treatment in women with early EC (408 patients) or atypical EH (151 patients) [72]. Endocrine treatment achieved a pooled regression rate of $76 \%$, a relapse rate of $41 \%$, and a live birth rate of $28 \%$. Twenty women were diagnosed with ovarian cancer (concurrent or metastatic) during follow-up (4\%) and 10 progressed to higher than stage I EC (2\%), among whom 2 women died. These data show that endocrine treatment of early stage EC is feasible, but is associated with a significant morbidity and mortality, which can be estimated at around 1 in 200 . Wei et al. found a similar efficacy of progestins in women with EC G1 or atypical EH summarizing 28 studies with 1038 patients [73]. Specifically, women with EC G1 or atypical EH had a pooled rate of complete regression (CR) of $71 \%$. Although $34 \%$ of women became pregnant, only $20 \%$ of them delivered live newborns. The CR rate for women using progestin plus IUD was higher than for IUD alone (87\% versus $76 \%$ ).

A Cochrane meta-analysis compared oral and intrauterine progestins for atypical EH and included only one randomized trial in which a levonorgestrel-releasing intrauterine device (LNG-IUD) was found to be superior to 


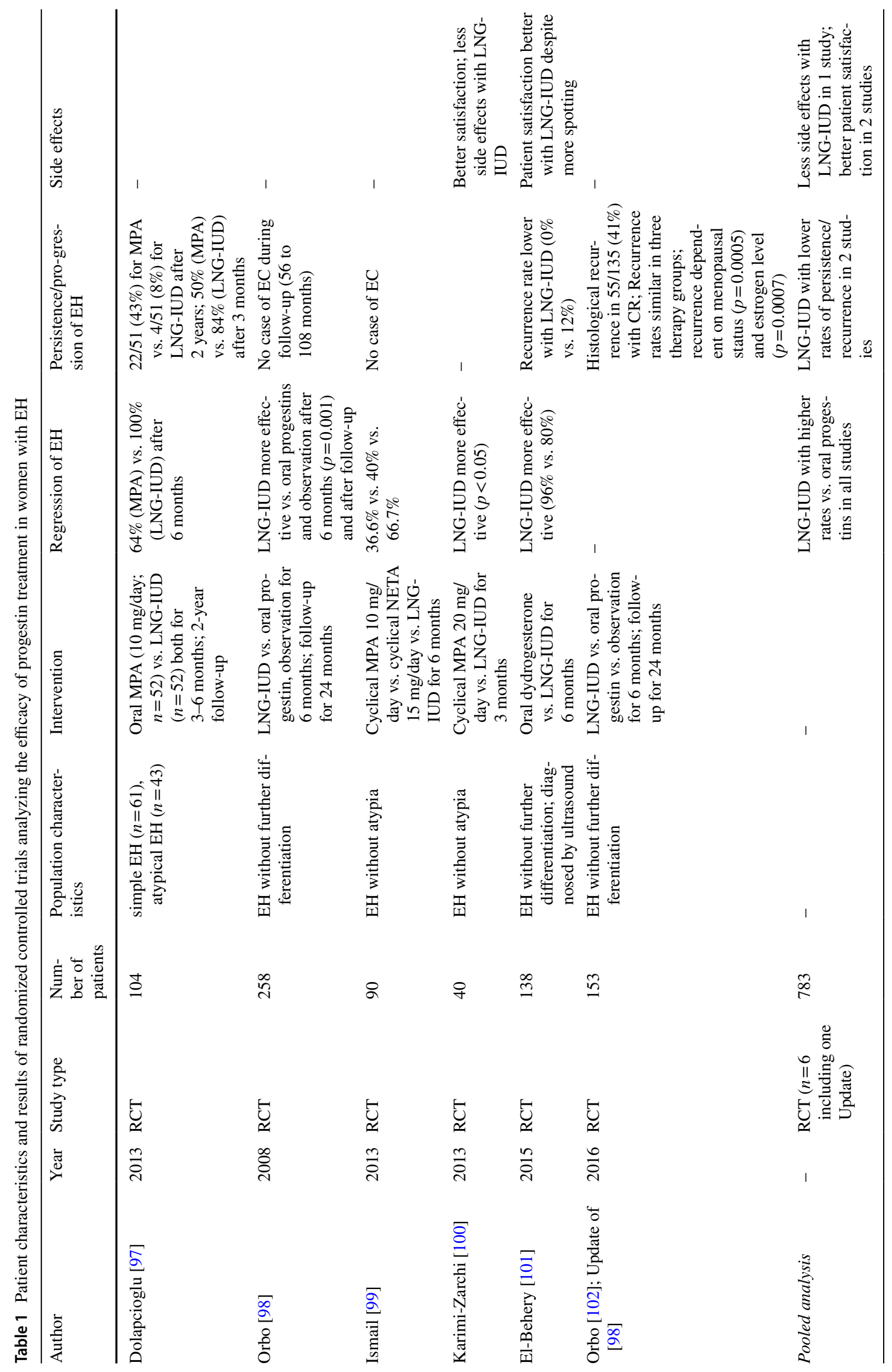




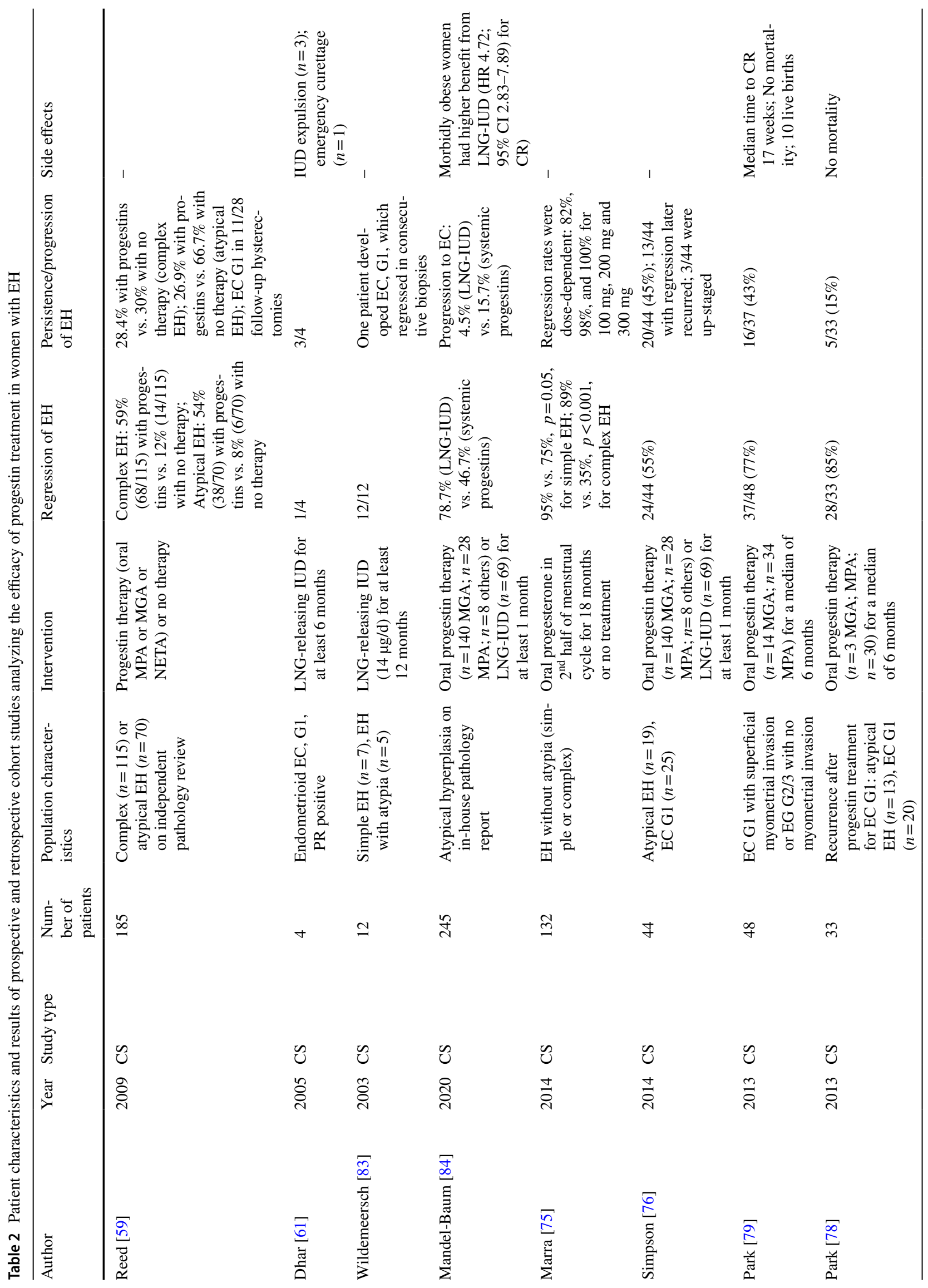




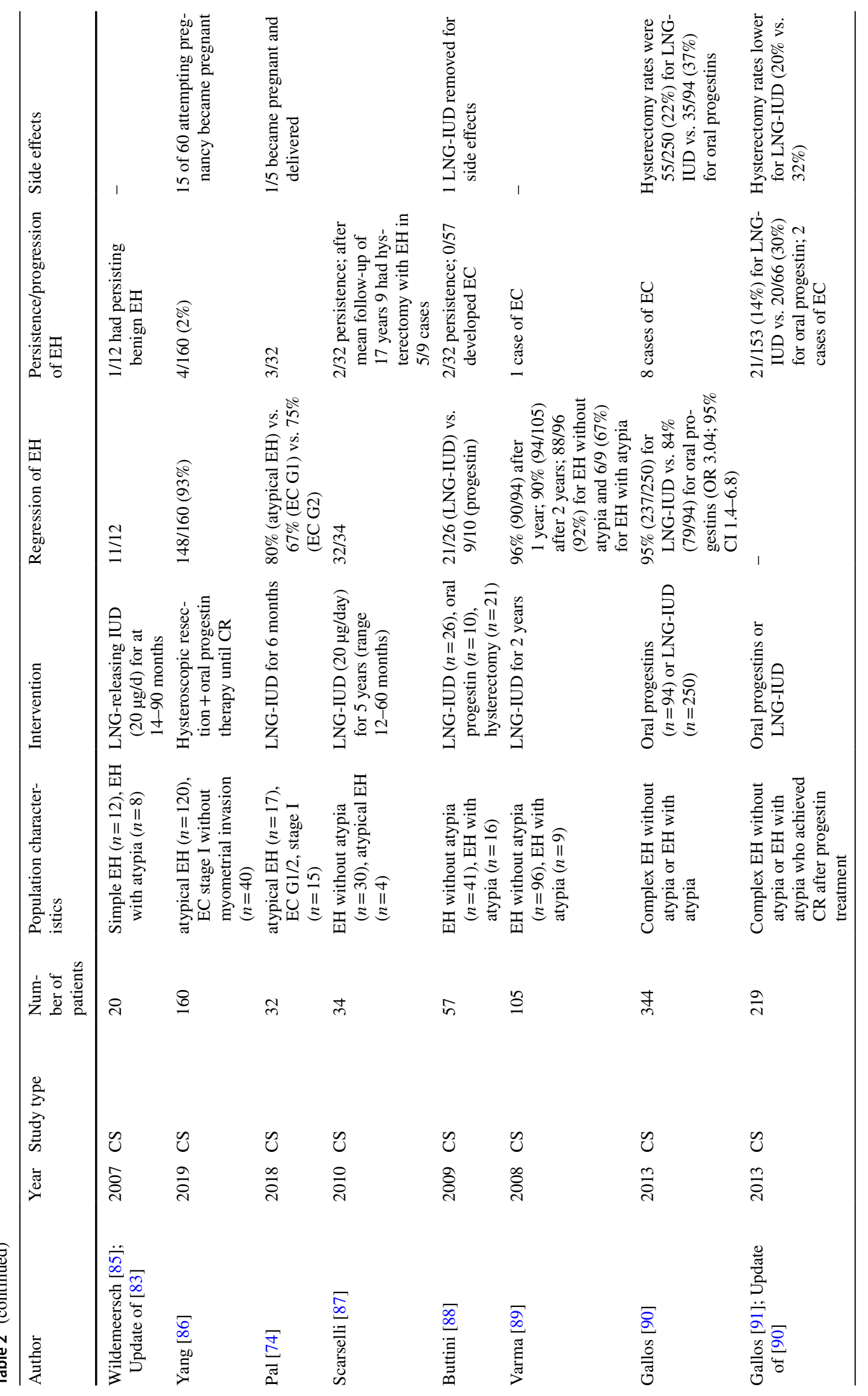




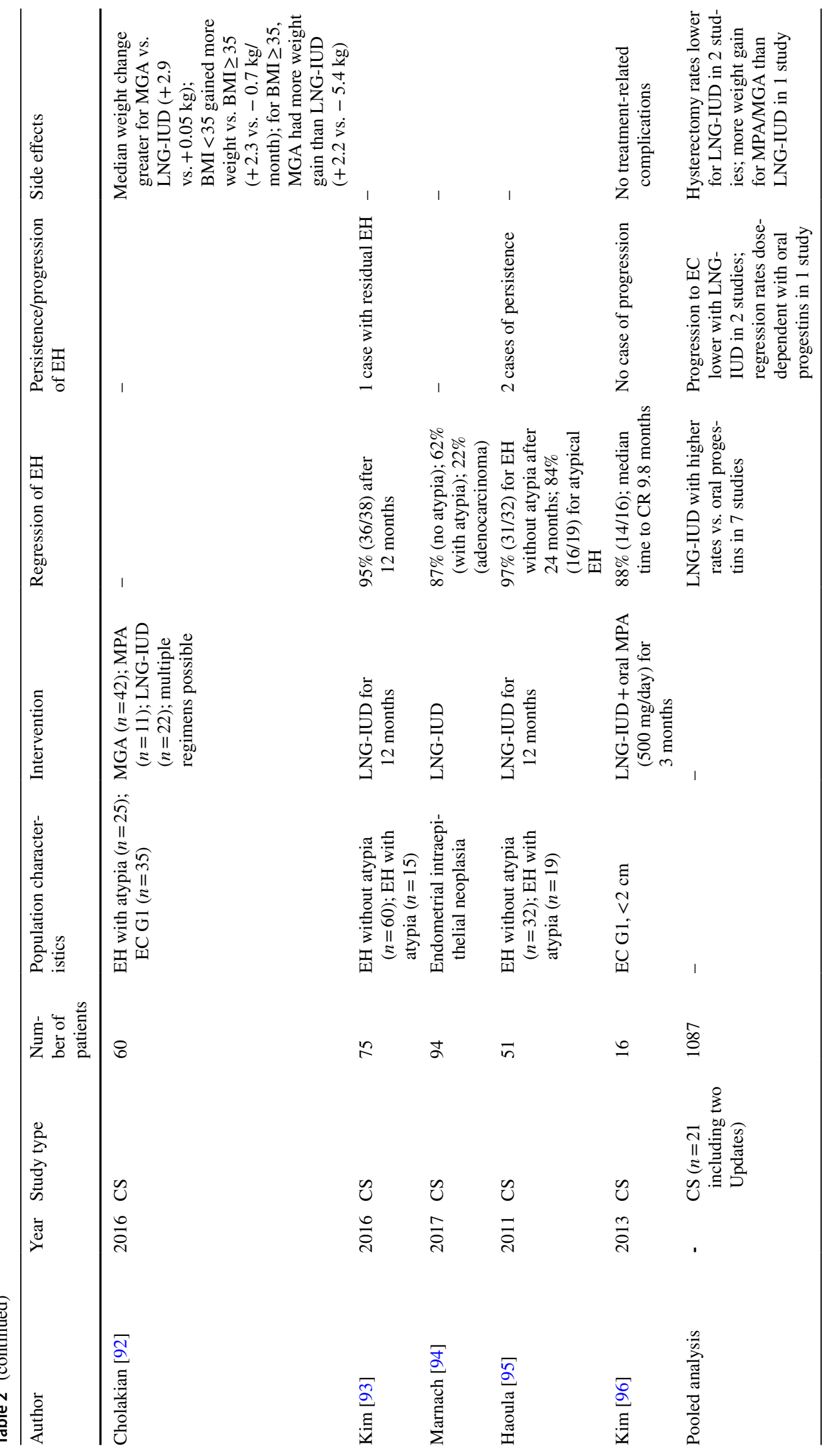


oral medroxyprogesterone acetate (MPA) [82]. In a more recent systematic review and meta-analysis, this finding was confirmed by Yuk et al. [75]. That meta-analysis included five RCTs with 377 patients. Here, the regression rate in women using the LNG-IUD was higher than for oral MPA among lean women (relative risk [RR] 1.41; 95\% CI 1.23-1.62), whereas the two regression rates, for LNGIUD and oral MPA, were similar among obese women (RR 1.03; 95\% CI 0.94-1.13). The LNG-IUD treatment was also superior in nonatypical EH (RR 1.36; 95\% CI 1.07-1.73) and mixed EH (atypical and non-atypical) (RR 1.44 ; 95\% CI 1.21-1.71).

There is weak evidence from a meta-analysis of two RCTs with 59 patients that metformin may be equally as effective as megestrol acetate (MGA) for the treatment of EH [76].

\section{Conclusion}

In summary, the available data from individual studies (Table 1) and meta-analyses clearly show that progestins are a safe and very effective treatment in patients with EH without atypia. In these patients, oral progestins achieve regression rates of around $85 \%$ and the LNG-IUD achieves regression rates of up to $100 \%$. In contrast, the efficacy of progestins is significantly lower in patients with atypical EH or EC G1. In these patients, regression rates between 70 and $85 \%$ may be expected and recurrence rates are high at to $40 \%$. Treatment with the LNG-IUD seems to be more effective than oral progestins in patients with atypical EH or EC G1. The rates of live births after treatment are low at around $20 \%$. Obese women gain more benefit from progestin treatment due to the higher relative background risk, but the treatment efficacy of progestins is higher in lean women. Additionally and notably, endocrine treatment of atypical EH or EC G1 carries a clinically relevant risk of mortality, which can be estimated as 1 in 200. Therefore, patients with atypical EH or EC G1 attempting treatment with progestins should be made aware of the low live-birth rates, the high recurrence risk, and the mortality associated with this kind of treatment. The standard of care for patients with atypical EH or EC G1 remains total hysterectomy.

Author contribution L.K.N. and C.B.T. performed the literature research and wrote the manuscript with support from M.W. All authors contributed to the final manuscript.

Funding Open Access funding enabled and organized by Projekt DEAL.

\section{Declarations}

Conflict of interest The authors declare no conflict of interest.

Ethical approval This article does not contain any studies with human participants or animals performed by any of the authors.

Availability of data and materials Not applicable.

Open Access This article is licensed under a Creative Commons Attribution 4.0 International License, which permits use, sharing, adaptation, distribution and reproduction in any medium or format, as long as you give appropriate credit to the original author(s) and the source, provide a link to the Creative Commons licence, and indicate if changes were made. The images or other third party material in this article are included in the article's Creative Commons licence, unless indicated otherwise in a credit line to the material. If material is not included in the article's Creative Commons licence and your intended use is not permitted by statutory regulation or exceeds the permitted use, you will need to obtain permission directly from the copyright holder. To view a copy of this licence, visit http://creativecommons.org/licenses/by/4.0/.

\section{References}

1. Kurman RJ, Norris HJ (1982) Evaluation of criteria for distinguishing atypical endometrial hyperplasia from well-differentiated carcinoma. Cancer 49(12):2547-2559

2. Gunderson CC, Fader AN, Carson KA, Bristow RE (2012) Oncologic and reproductive outcomes with progestin therapy in women with endometrial hyperplasia and grade 1 adenocarcinoma: a systematic review. Gynecol Oncol 125(2):477-482

3. Kurman RJ, Kaminski PF, Norris HJ: The behavior of endometrial hyperplasia. A long-term study of "untreated" hyperplasia in 170 patients. Cancer 1985, 56(2):403-412.

4. Cancer Genome Atlas Research N, Kandoth C, Schultz N, Cherniack AD, Akbani R, Liu Y, Shen H, Robertson AG, Pashtan I, Shen R et al: Integrated genomic characterization of endometrial carcinoma. Nature 2013, 497(7447):67-73.

5. Rakha E, Wong SC, Soomro I, Chaudry Z, Sharma A, Deen S, Chan S, Abu J, Nunns D, Williamson K et al (2012) Clinical outcome of atypical endometrial hyperplasia diagnosed on an endometrial biopsy: institutional experience and review of literature. Am J Surg Pathol 36(11):1683-1690

6. Silverberg SG (2000) Problems in the differential diagnosis of endometrial hyperplasia and carcinoma. Mod Pathol 13(3):309-327

7. Soslow RA (2006) Problems with the current diagnostic approach to complex atypical endometrial hyperplasia. Cancer 106(4):729-731

8. Shutter J, Wright TC Jr (2005) Prevalence of underlying adenocarcinoma in women with atypical endometrial hyperplasia. Int J Gynecol Pathol 24(4):313-318

9. Valenzuela P, Sanz JM, Keller J (2003) Atypical endometrial hyperplasia: grounds for possible misdiagnosis of endometrial adenocarcinoma. Gynecol Obstet Invest 56(3):163-167

10. Vereide AB, Arnes M, Straume B, Maltau JM, Orbo A (2003) Nuclear morphometric changes and therapy monitoring in patients with endometrial hyperplasia: a study comparing effects of intrauterine levonorgestrel and systemic medroxyprogesterone. Gynecol Oncol 91(3):526-533 
11. Lacey JV Jr, Sherman ME, Rush BB, Ronnett BM, Ioffe OB, Duggan MA, Glass AG, Richesson DA, Chatterjee N, Langholz B (2010) Absolute risk of endometrial carcinoma during 20-year follow-up among women with endometrial hyperplasia. Journal of clinical oncology : official journal of the American Society of Clinical Oncology 28(5):788-792

12. Reed SD, Newton KM, Garcia RL, Allison KH, Voigt LF, Jordan CD, Epplein M, Swisher E, Upson K, Ehrlich KJ et al (2010) Complex hyperplasia with and without atypia: clinical outcomes and implications of progestin therapy. Obstet Gynecol 116(2 Pt 1):365-373

13. Trimble CL, Kauderer J, Zaino R, Silverberg S, Lim PC, Burke JJ 2nd, Alberts D, Curtin J (2006) Concurrent endometrial carcinoma in women with a biopsy diagnosis of atypical endometrial hyperplasia: a Gynecologic Oncology Group study. Cancer 106(4):812-819

14. Brinton LA, Berman ML, Mortel R, Twiggs LB, Barrett RJ, Wilbanks GD, Lannom L, Hoover RN (1992) Reproductive, menstrual, and medical risk factors for endometrial cancer: results from a case-control study. Am J Obstet Gynecol 167(5):1317-1325

15. Zeleniuch-Jacquotte A, Akhmedkhanov A, Kato I, Koenig KL, Shore RE, Kim MY, Levitz M, Mittal KR, Raju U, Banerjee S et al (2001) Postmenopausal endogenous oestrogens and risk of endometrial cancer: results of a prospective study. Br J Cancer 84(7):975-981

16. Lukanova A, Lundin E, Micheli A, Arslan A, Ferrari P, Rinaldi S, Krogh V, Lenner P, Shore RE, Biessy C et al (2004) Circulating levels of sex steroid hormones and risk of endometrial cancer in postmenopausal women. Int J Cancer 108(3):425-432

17. Nyholm HC, Nielsen AL, Lyndrup J, Dreisler A, Hagen C, Haug E (1993) Plasma oestrogens in postmenopausal women with endometrial cancer. Br J Obstet Gynaecol 100(12):1115-1119

18. Potischman N, Hoover RN, Brinton LA, Siiteri P, Dorgan JF, Swanson CA, Berman ML, Mortel R, Twiggs LB, Barrett RJ et al (1996) Case-control study of endogenous steroid hormones and endometrial cancer. J Natl Cancer Inst 88(16):1127-1135

19. Tzortzatos G, Andersson E, Soller M, Askmalm MS, Zagoras T, Georgii-Hemming P, Lindblom A, Tham E, Mints M (2015) The gynecological surveillance of women with Lynch syndrome in Sweden. Gynecol Oncol 138(3):717-722

20. Pilarski R, Stephens JA, Noss R, Fisher JL, Prior TW (2011) Predicting PTEN mutations: an evaluation of Cowden syndrome and Bannayan-Riley-Ruvalcaba syndrome clinical features. J Med Genet 48(8):505-512

21. Riegert-Johnson DL, Gleeson FC, Roberts M, Tholen K, Youngborg L, Bullock M, Boardman LA (2010) Cancer and LhermitteDuclos disease are common in Cowden syndrome patients. Hered Cancer Clin Pract 8(1):6

22. Heald B, Mester J, Rybicki L, Orloff MS, Burke CA, Eng C (2010) Frequent gastrointestinal polyps and colorectal adenocarcinomas in a prospective series of PTEN mutation carriers. Gastroenterology 139(6):1927-1933

23. Siiteri PK (1987) Adipose tissue as a source of hormones. Am J Clin Nutr 45(1 Suppl):277-282

24. Wise MR, Gill P, Lensen S, Thompson JM, Farquhar CM: Body mass index trumps age in decision for endometrial biopsy: cohort study of symptomatic premenopausal women. American journal of obstetrics and gynecology 2016, 215(5):598 e591-598 e598.

25. Chittenden BG, Fullerton G, Maheshwari A, Bhattacharya S (2009) Polycystic ovary syndrome and the risk of gynaecological cancer: a systematic review. Reprod Biomed Online 19(3):398-405
26. Haoula Z, Salman M, Atiomo W (2012) Evaluating the association between endometrial cancer and polycystic ovary syndrome. Hum Reprod 27(5):1327-1331

27. Barry JA, Azizia MM, Hardiman PJ (2014) Risk of endometrial, ovarian and breast cancer in women with polycystic ovary syndrome: a systematic review and meta-analysis. Hum Reprod Update 20(5):748-758

28. Rosen MW, Tasset J, Kobernik EK, Smith YR, Johnston C, Quint EH (2019) Risk factors for endometrial cancer or hyperplasia in adolescents and women 25 years old or younger. J Pediatr Adolesc Gynecol 32(5):546-549

29. Schumer ST, Cannistra SA (2003) Granulosa cell tumor of the ovary. Journal of clinical oncology : official journal of the American Society of Clinical Oncology 21(6):1180-1189

30. Zanagnolo V, Pasinetti B, Sartori E (2004) Clinical review of 63 cases of sex cord stromal tumors. Eur J Gynaecol Oncol 25(4):431-438

31. Furness S, Roberts H, Marjoribanks J, Lethaby A, Hickey M, Farquhar C: Hormone therapy in postmenopausal women and risk of endometrial hyperplasia. Cochrane Database Syst Rev 2009(2):CD000402.

32. Henderson BE (1989) The cancer question: an overview of recent epidemiologic and retrospective data. Am J Obstet Gynecol 161(6 Pt 2):1859-1864

33. Persson I, Adami HO, Bergkvist L, Lindgren A, Pettersson B, Hoover R, Schairer C (1989) Risk of endometrial cancer after treatment with oestrogens alone or in conjunction with progestogens: results of a prospective study. BMJ 298(6667):147-151

34. Beral V, Bull D, Reeves G (2005) Million Women Study C: Endometrial cancer and hormone-replacement therapy in the Million Women Study. Lancet (London, England) 365(9470):1543-1551

35. Weiderpass E, Adami HO, Baron JA, Magnusson C, Bergstrom R, Lindgren A, Correia N, Persson I (1999) Risk of endometrial cancer following estrogen replacement with and without progestins. J Natl Cancer Inst 91(13):1131-1137

36. Strom BL, Schinnar R, Weber AL, Bunin G, Berlin JA, Baumgarten M, DeMichele A, Rubin SC, Berlin M, Troxel AB et al (2006) Case-control study of postmenopausal hormone replacement therapy and endometrial cancer. Am J Epidemiol 164(8):775-786

37. Committee Opinion No (2014) 601: Tamoxifen and uterine cancer. Obstet Gynecol 123(6):1394-1397

38. Fisher B, Costantino JP, Redmond CK, Fisher ER, Wickerham DL, Cronin WM (1994) Endometrial cancer in tamoxifen-treated breast cancer patients: findings from the National Surgical Adjuvant Breast and Bowel Project (NSABP) B-14. J Natl Cancer Inst 86(7):527-537

39. Jordan VC, Morrow M: Should clinicians be concerned about the carcinogenic potential of tamoxifen? European journal of cancer (Oxford, England : 1990) 1994, 30A(11):1714-1721.

40. Barakat RR, Wong G, Curtin JP, Vlamis V, Hoskins WJ (1994) Tamoxifen use in breast cancer patients who subsequently develop corpus cancer is not associated with a higher incidence of adverse histologic features. Gynecol Oncol 55(2):164-168

41. Bergman L, Beelen ML, Gallee MP, Hollema H, Benraadt J, van Leeuwen FE: Risk and prognosis of endometrial cancer after tamoxifen for breast cancer. Comprehensive Cancer Centres' ALERT Group. Assessment of Liver and Endometrial cancer Risk following Tamoxifen. Lancet (London, England) 2000, 356(9233):881-887.

42. Tamoxifen for early breast cancer: an overview of the randomised trials. Early Breast Cancer Trialists' Collaborative Group. Lancet (London, England) 1998, 351(9114):1451-1467.

43. Fisher B, Costantino JP, Wickerham DL, Redmond CK, Kavanah M, Cronin WM, Vogel V, Robidoux A, Dimitrov N, Atkins J et al (1998) Tamoxifen for prevention of breast cancer: report of the 
National Surgical Adjuvant Breast and Bowel Project P-1 Study. J Natl Cancer Inst 90(18):1371-1388

44. Cheng WF, Lin HH, Torng PL, Huang SC (1997) Comparison of endometrial changes among symptomatic tamoxifen-treated and nontreated premenopausal and postmenopausal breast cancer patients. Gynecol Oncol 66(2):233-237

45. Lancaster JM, Powell CB, Chen LM, Richardson DL (2015) Committee SGOCP: Society of Gynecologic Oncology statement on risk assessment for inherited gynecologic cancer predispositions. Gynecol Oncol 136(1):3-7

46. Ryan NAJ, McMahon R, Tobi S, Snowsill T, Esquibel S, Wallace AJ, Bunstone S, Bowers N, Mosneag IE, Kitson SJ et al: The proportion of endometrial tumours associated with Lynch syndrome (PETALS): A prospective cross-sectional study. PLoS Med 2020, 17(9):e1003263.

47. Post CCB, Stelloo E, Smit V, Ruano D, Tops CM, Vermij L, Rutten TA, Jurgenliemk-Schulz IM, Lutgens L, Jobsen JJ et al: Prevalence and Prognosis of Lynch Syndrome and Sporadic Mismatch Repair Deficiency in Endometrial Cancer. Journal of the National Cancer Institute 2021.

48. Schmeler KM, Lynch HT, Chen LM, Munsell MF, Soliman PT, Clark MB, Daniels MS, White KG, Boyd-Rogers SG, Conrad PG et al (2006) Prophylactic surgery to reduce the risk of gynecologic cancers in the Lynch syndrome. N Engl J Med 354(3):261-269

49. Zauber P, Denehy TR, Taylor RR, Ongcapin EH, Marotta S, Sabbath-Solitare M (2015) Strong correlation between molecular changes in endometrial carcinomas and concomitant hyperplasia. International journal of gynecological cancer : official journal of the International Gynecological Cancer Society 25(5):863-868

50. Horowitz N, Pinto K, Mutch DG, Herzog TJ, Rader JS, Gibb R, Bocker-Edmonston T, Goodfellow PJ (2002) Microsatellite instability, MLH1 promoter methylation, and loss of mismatch repair in endometrial cancer and concomitant atypical hyperplasia. Gynecol Oncol 86(1):62-68

51. Colombo N, Creutzberg C, Amant F, Bosse T, Gonzalez-Martin A, Ledermann J, Marth C, Nout R, Querleu D, Mirza MR et al: ESMO-ESGO-ESTRO Consensus Conference on Endometrial Cancer: diagnosis, treatment and follow-up. Annals of oncology : official journal of the European Society for Medical Oncology / ESMO 2016, 27(1):16-41.

52. Manchanda R, Saridogan E, Abdelraheim A, Johnson M, Rosenthal AN, Benjamin E, Brunell C, Side L, Gessler S, Jacobs I et al (2012) Annual outpatient hysteroscopy and endometrial sampling (OHES) in HNPCC/Lynch syndrome (LS). Arch Gynecol Obstet 286(6):1555-1562

53. Trimble CL, Method M, Leitao M, Lu K, Ioffe O, Hampton M, Higgins R, Zaino R, Mutter GL (2012) Society of Gynecologic Oncology Clinical Practice C: Management of endometrial precancers. Obstet Gynecol 120(5):1160-1175

54. Attard Montalto S, Coutts M, Devaja O, Summers J, Jyothirmayi R, Papadopoulos A (2008) Accuracy of frozen section diagnosis at surgery in pre- malignant and malignant lesions of the endometrium. Eur J Gynaecol Oncol 29(5):435-440

55. Salman MC, Usubutun A, Dogan NU, Yuce K (2009) The accuracy of frozen section analysis at hysterectomy in patients with atypical endometrial hyperplasia. Clin Exp Obstet Gynecol 36(1):31-34

56. Morotti M, Menada MV, Moioli M, Sala P, Maffeo I, Abete L, Fulcheri E, Menoni S, Venturini P, Papadia A (2012) Frozen section pathology at time of hysterectomy accurately predicts endometrial cancer in patients with preoperative diagnosis of atypical endometrial hyperplasia. Gynecol Oncol 125(3):536-540

57. Indermaur MD, Shoup B, Tebes S, Lancaster JM (2007) The accuracy of frozen pathology at time of hysterectomy in patients with complex atypical hyperplasia on preoperative biopsy. Am J Obstet Gynecol 196(5):e40-42

58. Weng CH, Wu RC, Chen SJ, Chen HC, Tan KT, Lee YS, Huang SS, Yang LY, Wang CJ, Chou HH et al: Molecular evidence for a clonal relationship between synchronous uterine endometrioid carcinoma and ovarian clear cell carcinoma: a new example of "precursor escape"? Journal of molecular medicine (Berlin, Germany) 2021.

59. Reed SD, Voigt LF, Newton KM, Garcia RH, Allison HK, Epplein M, Jordan D, Swisher E, Weiss NS (2009) Progestin therapy of complex endometrial hyperplasia with and without atypia. Obstet Gynecol 113(3):655-662

60. Montz FJ, Bristow RE, Bovicelli A, Tomacruz R, Kurman RJ (2002) Intrauterine progesterone treatment of early endometrial cancer. Am J Obstet Gynecol 186(4):651-657

61. Dhar KK, NeedhiRajan T, Koslowski M, Woolas RP (2005) Is levonorgestrel intrauterine system effective for treatment of early endometrial cancer? Report of four cases and review of the literature. Gynecol Oncol 97(3):924-927

62. McCawley GM, Ferriss JS, Geffel D, Northup CJ, Modesitt SC (2009) Cancer in obese women: potential protective impact of bariatric surgery. J Am Coll Surg 208(6):1093-1098

63. Alonso S, Castellanos T, Lapuente F, Chiva L (2015) Hysteroscopic surgery for conservative management in endometrial cancer: a review of the literature. Ecancermedicalscience 9:505

64. Wildemeersch D, Dhont M (2003) Treatment of nonatypical and atypical endometrial hyperplasia with a levonorgestrel-releasing intrauterine system. Am J Obstet Gynecol 188(5):1297-1298

65. Abu Hashim H, Ghayaty E, El Rakhawy M (2015) Levonorgestrel-releasing intrauterine system vs oral progestins for non-atypical endometrial hyperplasia: a systematic review and metaanalysis of randomized trials. Am J Obstet Gynecol 213(4):469-478

66. Gallos ID, Shehmar M, Thangaratinam S, Papapostolou TK, Coomarasamy A, Gupta JK: Oral progestogens vs levonorgestrelreleasing intrauterine system for endometrial hyperplasia: a systematic review and metaanalysis. American journal of obstetrics and gynecology 2010, 203(6):547 e541-510.

67. Ferenczy A, Gelfand M (1989) The biologic significance of cytologic atypia in progestogen-treated endometrial hyperplasia. Am J Obstet Gynecol 160(1):126-131

68. Affinito P, Di Carlo C, Di Mauro P, Napolitano V, Nappi C (1994) Endometrial hyperplasia: efficacy of a new treatment with a vaginal cream containing natural micronized progesterone. Maturitas 20(2-3):191-198

69. Perino A, Quartararo P, Catinella E, Genova G, Cittadini E (1987) Treatment of endometrial hyperplasia with levonorgestrel releasing intrauterine devices. Acta Eur Fertil 18(2):137-140

70. Arafat ES, Hargrove JT, Maxson WS, Desiderio DM, Wentz AC, Andersen RN (1988) Sedative and hypnotic effects of oral administration of micronized progesterone may be mediated through its metabolites. Am J Obstet Gynecol 159(5):1203-1209

71. Bourgain C, Devroey P, Van Waesberghe L, Smitz J, Van Steirteghem AC (1990) Effects of natural progesterone on the morphology of the endometrium in patients with primary ovarian failure. Hum Reprod 5(5):537-543

72. Gallos ID, Yap J, Rajkhowa M, Luesley DM, Coomarasamy A, Gupta JK: Regression, relapse, and live birth rates with fertilitysparing therapy for endometrial cancer and atypical complex endometrial hyperplasia: a systematic review and metaanalysis. American journal of obstetrics and gynecology 2012, 207(4):266 e261-212.

73. Wei J, Zhang W, Feng L, Gao W: Comparison of fertility-sparing treatments in patients with early endometrial cancer and atypical 
complex hyperplasia: A meta-analysis and systematic review. Medicine (Baltimore) 2017, 96(37):e8034.

74. Pal N, Broaddus RR, Urbauer DL, Balakrishnan N, Milbourne A, Schmeler KM, Meyer LA, Soliman PT, Lu KH, Ramirez PT et al (2018) Treatment of low-risk endometrial cancer and complex atypical hyperplasia with the levonorgestrel-releasing intrauterine device. Obstet Gynecol 131(1):109-116

75. Marra C, Penati C, Ferrari L, Cantu MG, Bargossi L, Fruscio R (2014) Treatment of simple and complex endometrial nonatypical hyperplasia with natural progesterone: response rate to different doses. Gynecol Endocrinol 30(12):899-901

76. Simpson AN, Feigenberg T, Clarke BA, Gien LT, Ismiil N, Laframboise S, Massey C, Ferguson SE (2014) Fertility sparing treatment of complex atypical hyperplasia and low grade endometrial cancer using oral progestin. Gynecol Oncol 133(2):229-233

77. Schindler AE (2013) Non-contraceptive benefits of oral hormonal contraceptives. Int J Endocrinol Metab 11(1):41-47

78. Park JY, Lee SH, Seong SJ, Kim DY, Kim TJ, Kim JW, Kim JH, Kim YM, Kim YT, Bae DS et al (2013) Progestin re-treatment in patients with recurrent endometrial adenocarcinoma after successful fertility-sparing management using progestin. Gynecol Oncol 129(1):7-11

79. Park JY, Kim DY, Kim TJ, Kim JW, Kim JH, Kim YM, Kim YT, Bae DS, Nam JH (2013) Hormonal therapy for women with stage IA endometrial cancer of all grades. Obstet Gynecol 122(1):7-14

80. Yuk JS, Song JY, Lee JH, Park WI, Ahn HS, Kim HJ (2017) Levonorgestrel-releasing intrauterine systems versus oral cyclic medroxyprogesterone acetate in endometrial hyperplasia therapy: a meta-analysis. Ann Surg Oncol 24(5):1322-1329

81. Clement NS, Oliver TR, Shiwani H, Sanner JR, Mulvaney CA, Atiomo W: Metformin for endometrial hyperplasia. Cochrane Database Syst Rev 2017, 10:CD012214.

82. Luo L, Luo B, Zheng Y, Zhang H, Li J, Sidell N: Oral and intrauterine progestogens for atypical endometrial hyperplasia. Cochrane Database Syst Rev 2018, 12:CD009458.

83. Wildemeersch D, Batar I, Affandi B, Andrade A, Shangchun W, Jing H, Xiaoming C (2003) The "frameless" intrauterine system for long-term, reversible contraception: a review of 15 years of clinical experience. J Obstet Gynaecol Res 29(3):164-173

84. Mandelbaum RS, Ciccone MA, Nusbaum DJ, Khoshchehreh M, Purswani H, Morocco EB, Smith MB, Matsuzaki S, Dancz CE, Ozel B et al: Progestin therapy for obese women with complex atypical hyperplasia: levonorgestrel-releasing intrauterine device vs systemic therapy. American journal of obstetrics and gynecology 2020, 223(1):103 e101-103 e113.

85. Wildemeersch D, Janssens D, Pylyser K, De Wever N, Verbeeck G, Dhont M, Tjalma W (2007) Management of patients with non-atypical and atypical endometrial hyperplasia with a levonorgestrel-releasing intrauterine system: long-term follow-up. Maturitas 57(2):210-213

86. Yang B, Xu Y, Zhu Q, Xie L, Shan W, Ning C, Xie B, Shi Y, Luo $\mathrm{X}$, Zhang $\mathrm{H}$ et al (2019) Treatment efficiency of comprehensive hysteroscopic evaluation and lesion resection combined with progestin therapy in young women with endometrial atypical hyperplasia and endometrial cancer. Gynecol Oncol 153(1):55-62

87. Scarselli G, Bargelli G, Taddei GL, Marchionni M, Peruzzi E, Pieralli A, Mattei A, Buccoliero AM, Fambrini M (2011) Levonorgestrel-releasing intrauterine system (LNG-IUS) as an effective treatment option for endometrial hyperplasia: a 15-year follow-up study. Fertil Steril 95(1):420-422

88. Buttini MJ, Jordan SJ, Webb PM (2009) The effect of the levonorgestrel releasing intrauterine system on endometrial hyperplasia: an Australian study and systematic review. Aust N Z J Obstet Gynaecol 49(3):316-322
89. Varma R, Soneja H, Bhatia K, Ganesan R, Rollason T, Clark TJ, Gupta JK (2008) The effectiveness of a levonorgestrel-releasing intrauterine system (LNG-IUS) in the treatment of endometrial hyperplasia-a long-term follow-up study. Eur J Obstet Gynecol Reprod Biol 139(2):169-175

90. Gallos ID, Krishan P, Shehmar M, Ganesan R, Gupta JK (2013) LNG-IUS versus oral progestogen treatment for endometrial hyperplasia: a long-term comparative cohort study. Hum Reprod 28(11):2966-2971

91. Gallos ID, Krishan P, Shehmar M, Ganesan R, Gupta JK (2013) Relapse of endometrial hyperplasia after conservative treatment: a cohort study with long-term follow-up. Hum Reprod 28(5):1231-1236

92. Cholakian D, Hacker K, Fader AN, Gehrig PA, Tanner EJ 3rd (2016) Effect of oral versus intrauterine progestins on weight in women undergoing fertility preserving therapy for complex atypical hyperplasia or endometrial cancer. Gynecol Oncol 140(2):234-238

93. Kim MK, Seong SJ, Kim JW, Jeon S, Choi HS, Lee IH, Lee JH, Ju W, Song ES, Park H et al (2016) Management of endometrial hyperplasia with a levonorgestrel-releasing intrauterine system: a Korean Gynecologic-Oncology Group Study. International journal of gynecological cancer : official journal of the International Gynecological Cancer Society 26(4):711-715

94. Marnach ML, Butler KA, Henry MR, Hutz CE, Langstraat CL, Lohse CM, Casey PM (2017) Oral progestogens versus levonorgestrel-releasing intrauterine system for treatment of endometrial intraepithelial neoplasia<sup/>. J Womens Health (Larchmt) 26(4):368-373

95. Haoula ZJ, Walker KF, Powell MC (2011) Levonorgestrel intrauterine system as a treatment option for complex endometrial hyperplasia. Eur J Obstet Gynecol Reprod Biol 159(1):176-179

96. Kim MK, Seong SJ, Kim YS, Song T, Kim ML, Yoon BS, Jun HS, Lee YH: Combined medroxyprogesterone acetate/levonorgestrel-intrauterine system treatment in young women with earlystage endometrial cancer. American journal of obstetrics and gynecology 2013, 209(4):358 e351-354.

97. Dolapcioglu K, Boz A, Baloglu A: The efficacy of intrauterine versus oral progestin for the treatment of endometrial hyperplasia. A prospective randomized comparative study. Clin Exp Obstet Gynecol 2013, 40(1):122-126.

98. Orbo A, Arnes M, Hancke C, Vereide AB, Pettersen I, Larsen K (2008) Treatment results of endometrial hyperplasia after prospective D-score classification: a follow-up study comparing effect of LNG-IUD and oral progestins versus observation only. Gynecol Oncol 111(1):68-73

99. Ismail MT, Fahmy DM, Elshmaa NS (2013) Efficacy of levonorgestrel-releasing intrauterine system versus oral progestins in treatment of simple endometrial hyperplasia without atypia. Reprod Sci 20(1):45-50

100. Karimi-Zarchi M, Dehghani-Firoozabadi R, Tabatabaie A, Dehghani-Firoozabadi Z, Teimoori S, Chiti Z, Miratashi-Yazdi A, Dehghani A (2013) A comparison of the effect of levonorgestrel IUD with oral medroxyprogesterone acetate on abnormal uterine bleeding with simple endometrial hyperplasia and fertility preservation. Clin Exp Obstet Gynecol 40(3):421-424

101. El Behery MM, Saleh HS, Ibrahiem MA, Kamal EM, Kassem GA, Mohamed Mel S (2015) Levonorgestrel-releasing intrauterine device versus dydrogesterone for management of endometrial hyperplasia without atypia. Reprod Sci 22(3):329-334

102. Orbo A, Arnes M, Vereide AB, Straume B (2016) Relapse risk of endometrial hyperplasia after treatment with the levonorgestrelimpregnated intrauterine system or oral progestogens. BJOG 123(9):1512-1519

103. Kresowik J, Ryan GL, Van Voorhis BJ (2008) Progression of atypical endometrial hyperplasia to adenocarcinoma despite 
intrauterine progesterone treatment with the levonorgestrelreleasing intrauterine system. Obstet Gynecol 111(2 Pt 2):547-549
Publisher's Note Springer Nature remains neutral with regard to jurisdictional claims in published maps and institutional affiliations. 